\title{
Análise das flutuações do nível do mar no litoral de Santa Catarina
}

\author{
Carlos Eduardo Salles de Araújo'
}

\begin{abstract}
Resumo - As flutuações do nível do mar no litoral de Santa Catarina durante o outono de 2018 foram estudadas para se avaliar a contribuição dos fenômenos da maré meteorológica em relação às marés astronômicas previstas. As séries temporais das estações maregráficas oceânicas (Ilha da Paz, Balneário Camboriú, Imbituba e Balneário Rincão) foram consistidas, reamostradas para intervalos de 15 minutos e padronizadas pelo nível médio do mar. A maré meteorológica, avaliada para oscilações superiores ao período inercial da região, apresentou amplitudes de 30 a $40 \mathrm{~cm}$ em relação ao nível médio no mar e ocorreu em períodos que variaram de 5 a 10 dias, correspondendo à escala de passagem dos sistemas atmosféricos frontais. Observou-se uma redução das amplitudes das marés astronômicas em direção ao sul do estado, de forma que a contribuição relativa das marés meteorológicas na variação do nível do mar ultrapassa $90 \%$ em casos extremos. Com base nestes resultados recomenda-se cautela no uso das tábuas de maré astronômica, especialmente para navegação costeira durante a entrada e a saída de embarcações em estuários, baías e enseadas.
\end{abstract}

Termos de indexação: maré astronômica, maré meteorológica, navegação costeira.

\section{Sea Level Fluctuations on Santa Catarina State - Brazil}

Abstract - Sea level fluctuations on the coast of Santa Catarina during the fall of 2018 were studied to evaluate the contribution of the meteorological tidal phenomenum in comparison with predicted astronomical tides. The time series of the open sea tidal stations (Ilha da Paz, Balneário Camboriú, Imbituba and Balneário Rincão) were quality controlled, interpolated at 15-minute intervals and standardized by mean sea level. The storm surge, evaluated in the inertial scale, presented amplitudes of 30 to $40 \mathrm{~cm}$ in relation to the mean sea level and occurred in periods ranging from 5 to 10 days, corresponding to the temporal scale of the frontal atmospheric systems. There has been a reduction in the amplitude of astronomical tides towards the south of Santa Catarina, so that the relative contribution of the storm surges to sea level variation exceeds $90 \%$ in extreme cases. Based on these results, caution is advised in the use of astronomical tidal tables, especially for coastal navigation on inbound and outbound vessels in estuaries, bays and inlets.

Index terms: astronomical tide, meteorological tide, coastal navigation.

\section{Introdução}

As medições das marés ao longo da costa dão apoio a um grande número de atividades do nosso cotidiano e para a comunidade científica. A navegação segura das embarcações em portos de águas rasas e estuários requer conhecimento do horário de ocorrência e da altura das marés. Os engenheiros, por sua vez, precisam de informações históricas das flutuações do nível da maré para projetos costeiros como pontes, cais, píeres de atracação, plataformas de pesca, trapiches. Para a comunidade científica existem muitas aplicações para os dados de maré, como por exemplo: os ecologistas, oceanógrafos e biólogos estudam a mistura das águas costeiras promovida pelas correntes de maré, onde poluentes são removidos e nutrientes reciclados, impactando diretamente atividades como a pesca e a maricultura; os climatologistas precisam das informações de variação do nível do mar para estudar os impactos das mudanças climáticas em zonas costeiras, entre outros.

O nível do mar medido diretamente nas estações maregráficas ao longo da costa varia em decorrência da atuação de diferentes fenômenos naturais, dos quais os principais são a maré astronômica e a maré meteorológica.

A maré astronômica resulta da força de atração gravitacional que o Sol e a Lua exercem sobre os oceanos. Na costa sulsudeste do Brasil a principal componente da maré astronômica é a semidiurna, ou seja, as variações entre a maré baixa e a maré alta ocorrem aproximadamente de 6 em 6 horas, repetindo-se o ciclo a cada 12 horas (FRANCO, 1997). Outro ciclo importante da maré astronômica corresponde às fases da lua. Nas fases Nova e Cheia, o Sol e a Lua estão alinhados e as diferenças (altura) entre a maré baixa e a maré alta são maiores. Nas fases crescente e minguante o Sol e a Lua estão em ângulos retos e as amplitudes de maré são menores. Os períodos de maior amplitude são conhecidos como marés vivas ou de sizígia e os de menor amplitude como marés mortas ou de quadratura (PUGH, 1987). Os períodos 
de sizígia e quadratura se alteram aproximadamente a cada sete dias e o ciclo completo dura 29,5 dias (lunação).

A elevação do nível do mar, decorrente da ação combinada da pressão atmosférica e do empilhamento das águas gerado pelo vento, se propaga como uma onda ao longo do litoral e para baías interiores, de forma similar a uma maré astronômica (MESQUITA, 2003). Por apresentar o mesmo comportamento, o somatório destes efeitos é conhecido como maré meteorológica. A ação positiva combinada das marés astronômica e meteorológica pode causar inundação costeira (ESTEBAN et al., 2015). De forma inversa, a ação negativa combinada destas marés pode prejudicar a atividade portuária e de navegação.

O monitoramento e o estudo das variações do nível do mar são importantes para o uso racional da zona costeira. Aquicultura, navegação, turismo, pesca, erosão e obras na zona costeira são atividades desenvolvidas ao longo dos $450 \mathrm{Km}$ do litoral de Santa Catarina que dependem do monitoramento da maré. Com o propósito de atender a esta demanda a Empresa de Pesquisa Agropecuária e Extensão Rural de Santa Catarina (Epagri) começou a instalar em 2012 uma rede de monitoramento maregráfico que atualmente conta com onze estações operacionais: Passo de Torres, Balneário Rincão, Laguna, Imbituba, Sul da Ilha de Santa Catarina, Balneário Camboriú, Barra Velha, Ilha da Paz, Itapoá, São Francisco do Sul e Joinville.

A solução tecnológica compreende sensores de nível do tipo radar e piezelétrico; painel solar e bateria, tornandoos independentes em relação à energia; um datalogger, para armazenamento e processamento dos dados; modem GPRS para transmissão e finalmente um servidor para recebimento, qualificação e armazenamento dos dados (VANZ et al., 2017). As informações são coletadas de forma automática em intervalos de 5 minutos e a eficiência média de operação da rede é superior a $98 \%$, ou seja, dados espúrios e faltantes são inferiores a $2 \%$.

O diferencial da Epagri é disponibilizar informações atualizadas do nível do mar no sítio www.ciram.com.br/ litoral_online/ a cada hora. Com base nas séries históricas é feita anualmente a previsão da maré astronômica utilizando-se modelos matemáticos para extrair as constantes harmônicas. Estas previsões também são disponibilizadas pela Epagri no site.

\section{Material e métodos}

Na avaliação das variações do nível do mar neste estudo em Santa Catarina foram considerados apenas os marégrafos localizados em oceano aberto: Ilha da Paz, Balneário Camboriú, Imbituba e Balneário Rincão, conforme localização mostrada na Figura 1. Este procedimento visa evitar a influência de descargas fluviais dos rios e de fenômenos físicos que ocorrem no interior de baías, como

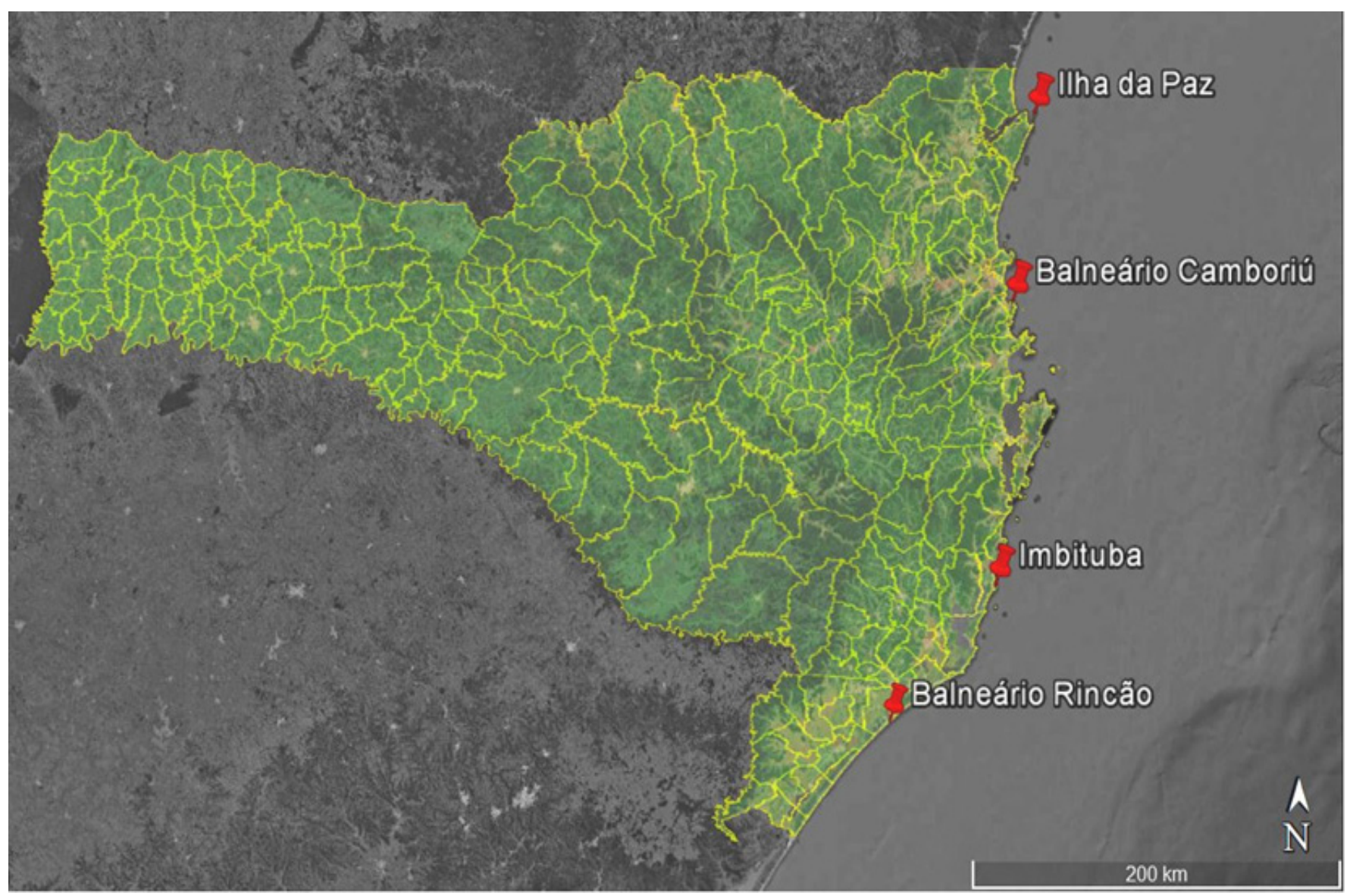

Figura 1. Localização das estações maregráficas.

Figure 1. Location of the tidal stations 
a refração e a reflexão das ondas de maré.

\section{Pré-processamento}

Os dados de nível do mar dados observados para o outono de 2018 foram consistidos para eliminar valores espúrios e depois reamostrados para intervalos de 15 minutos, preenchendo-se possíveis falhas nas séries. Um filtro de janela móvel do tipo Hamming (OPPENHEIM et al., 1999) com frequência de corte de $2,78 \times 10^{-4} \mathrm{~Hz}$ foi utilizado para reduzir os ruídos de alta frequência que são provocados pela ação das ondas geradas pelo vento e outras forças locais.

\section{Padronização do nível médio do mar}

O nível do mar medido pelos marégrafos é arbitrado em relação à menor baixa-mar de sizígia observada em cada localidade num período mínimo de seis meses (zero da escala vertical), de acordo com recomendação da Diretoria de Hidrografia e Navegação da Marinha do Brasil (DHN). Para permitir comparações entre as diferentes estações, os dados pré-processados são padronizados, subtraindo-se o nível médio do mar de cada estação, de forma que a referência do nível médio passa a ser o zero em todas as estações.

\section{Maré inercial (meteorológica)}

De acordo com Castelão \& Barth (2006), as variações do nível do mar provocadas pela ação das correntes marítimas geradas pelo vento na coluna d'água ocorrem em escalas de espaço e tempo onde o efeito de rotação da Terra desvia as correntes para a esquerda do vento no Hemisfério Sul. No litoral de Santa Catarina, os ventos que sopram de quadrante sul geram correntes nas camadas superficiais do mar (primeiras dezenas de metros) que empilham a água na costa e os ventos de quadrante norte afastam as camadas de águas superficiais da costa. A escala em que este fenômeno ocorre varia conforme a latitude da Terra. Em Santa Catarina é necessário que o vento sopre sobre a plataforma continental em escalas espaciais de muitas dezenas a poucas centenas de quilômetros e por períodos superiores a 25-27 horas.

Desta forma as chamadas marés meteorológicas ocorrem próximas à escala inercial, enquanto as marés astronômicas têm sua principal energia associada à variação semidiurna. Com o objetivo de separar e estimar a contribuição da maré meteorológica nas variações do nível do mar, aplica-se às séries de dados pré-processados um filtro de janela móvel de Hamming do tipo passa-baixa, com período de corte superior a 27 ho- ras. O sinal resultante corresponde à banda de frequência inercial da maré. As flutuações de maré suprainercial são comparadas no trimestre para as quatro estações maregráficas na forma de um gráfico temporal de linhas na seção Resultados.

\section{Resultados e discussão}

A Figura 2 apresenta, para todos os marégrafos, a contribuição dos períodos superiores a 27 horas (escala inercial) nas variações do nível do mar ao longo do outono de 2018.

A análise da Figura 2 mostra que os períodos de oscilação variaram de 5 a 10 dias, correspondendo ao período de passagem dos sistemas atmosféricos frontais relatados por Stech \& Lorenzzetti (1992) - 5 a 6 dias, Rodrigues et al. (2004) - 8 dias e Pampuch \& Ambrizzi (2015) - 8 a 11 dias. As amplitudes dos eventos mais significativos, tanto positivos quanto negativos, foram da ordem de 30 a $40 \mathrm{~cm}$ com extremos próximos a $50 \mathrm{~cm}$ registrados em Balneário Rincão.

As Figuras 3 a 6 apresentam, para as estações maregráficas da Ilha da Paz, Balneário Camboriú, Imbituba e Balneário Rincão respectivamente, gráficos de linha (tempo X nível do mar) sobrepondo as flutuações do nível do mar observadas e as marés inerciais (meteorológicas) calculadas.

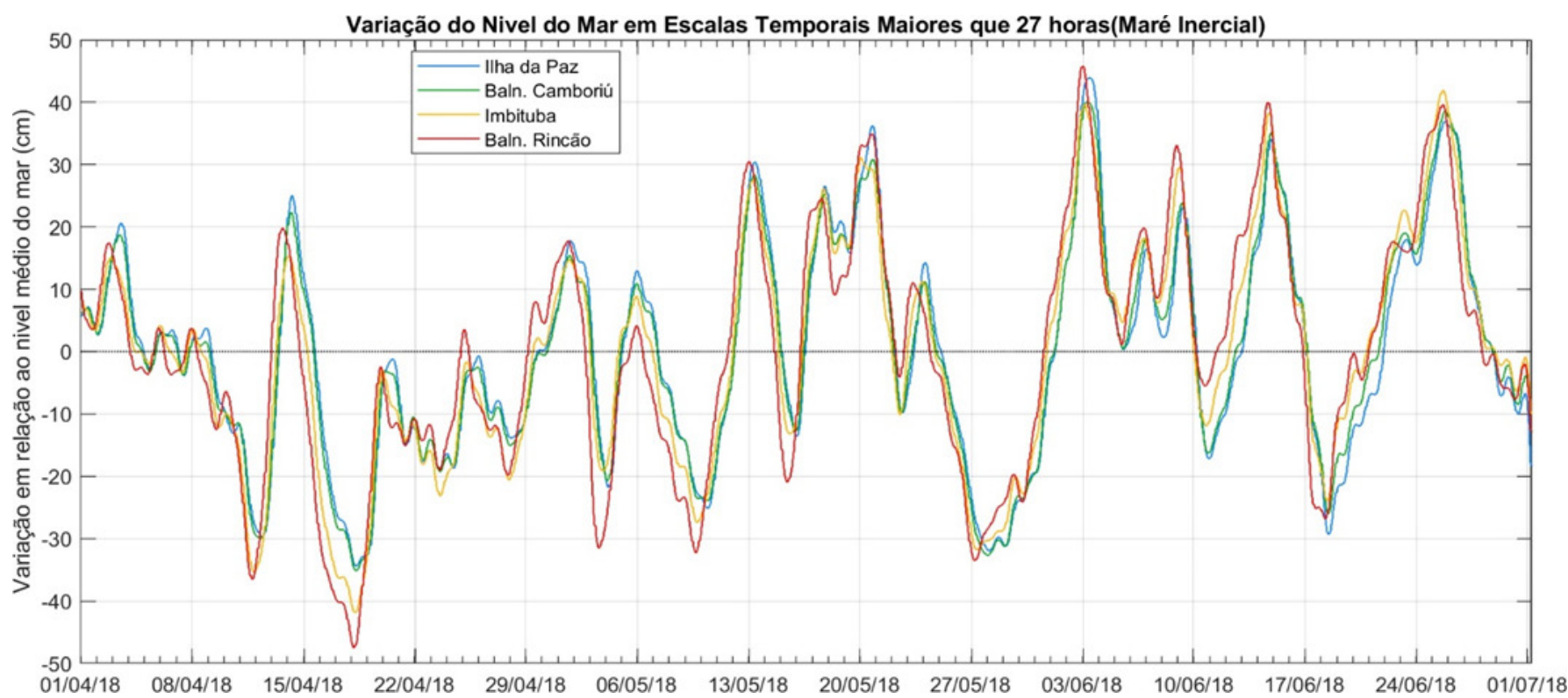

Figura 2. Variação do nível do mar na escala inercial

Figure 2. Sea Level variation on inertial scale 


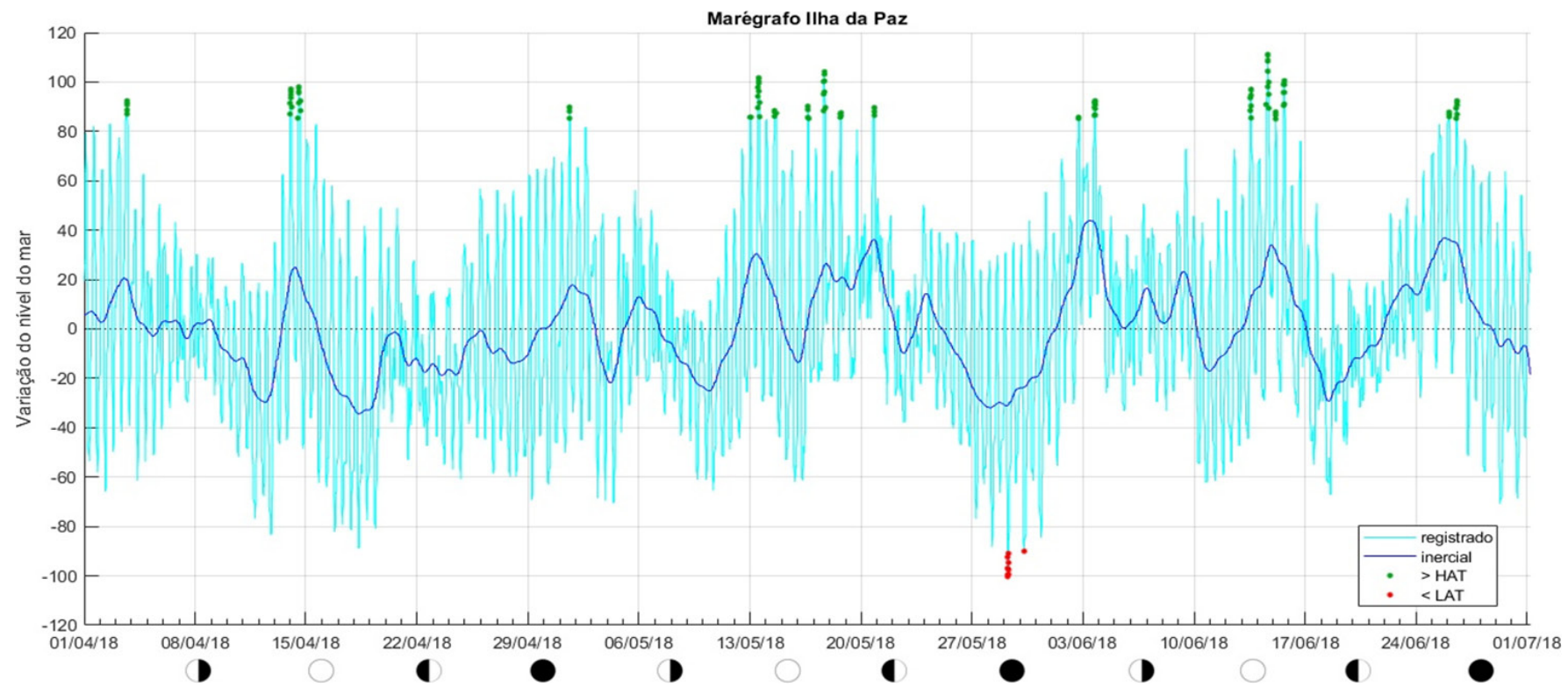

Figura 3. Flutuações do nível do mar, marés inerciais e eventos significativos observados na llha da Paz no outono de 2018

Figure 3. Sea level fluctuations, inertial tides and significant events observed at llha da Paz station in the fall of 2018

Tabela 1. Resumo dos eventos significativos observados na llha da Paz para o outono de 2018

Table 2. Summary of significant events in fall 2018 at the Paz island monitoring station

\begin{tabular}{|l|c|c|c|c|c|c|c|c|c|c|c|}
\hline & Eventos & Total_hr & $\begin{array}{c}\text { Horas_ } \\
\text { med }\end{array}$ & $\begin{array}{c}\text { Horas_ } \\
\text { max }\end{array}$ & Obs_med & Obs_max Inerc_med Inerc_max Perc_med Perc_max \\
\hline
\end{tabular}

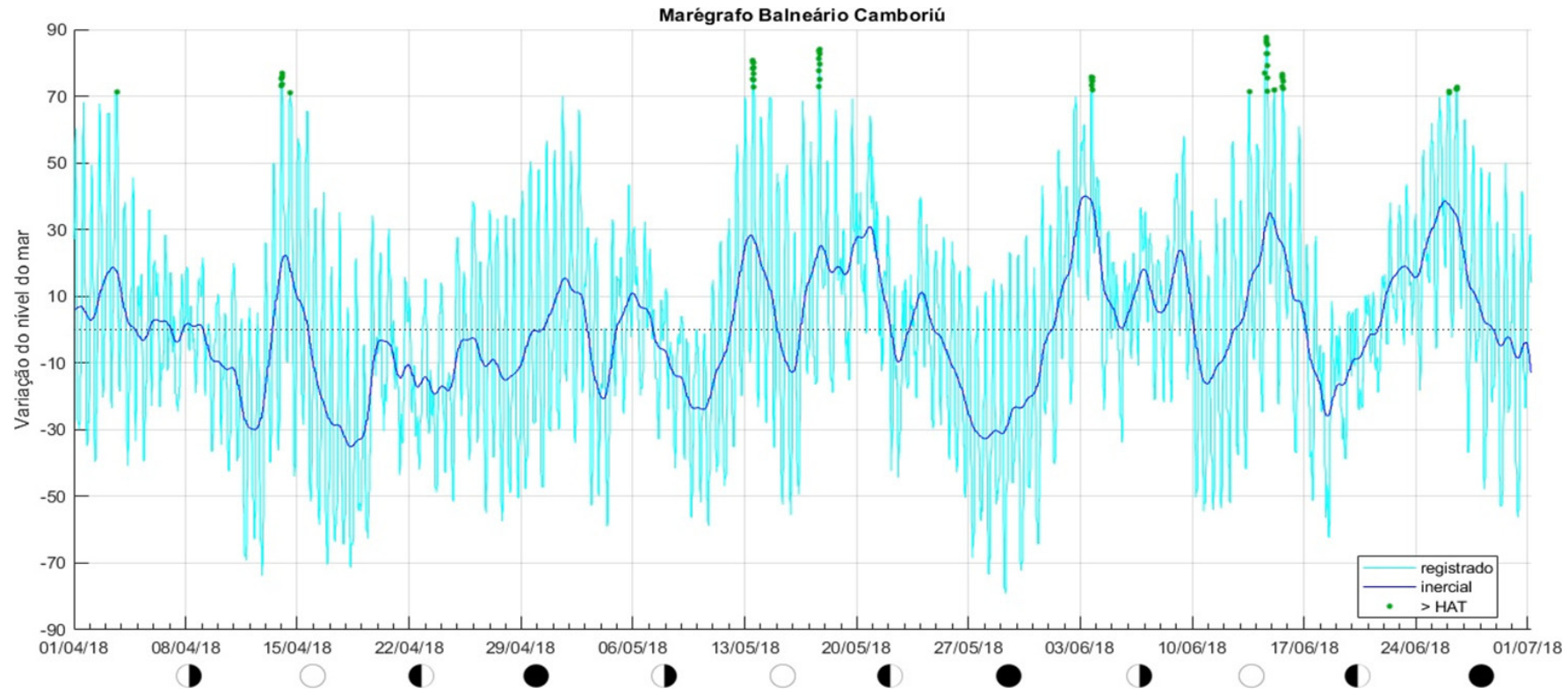

Figura 4. Flutuações do nível do mar, marés inerciais e eventos significativos observados em Balneário Camboriú no outono de 2018 Figure 4. Sea level fluctuations, inertial tides and significant events observed at Balneário Camboriú station in the fall of 2018 
Tabela 2. Resumo dos eventos significativos observados em Balneário Camboriú para o outono de 2018

Table 2. Summary of significant events in fall 2018 at Balneário Camboriú monitoring station

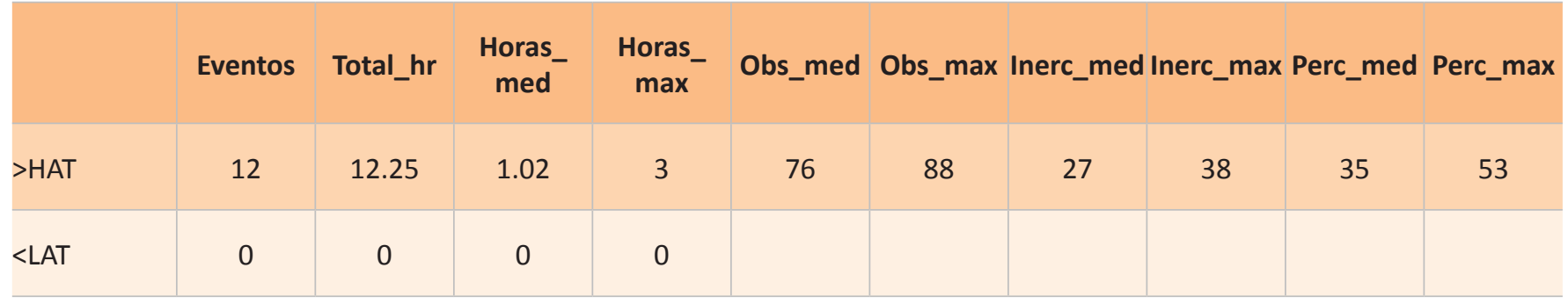

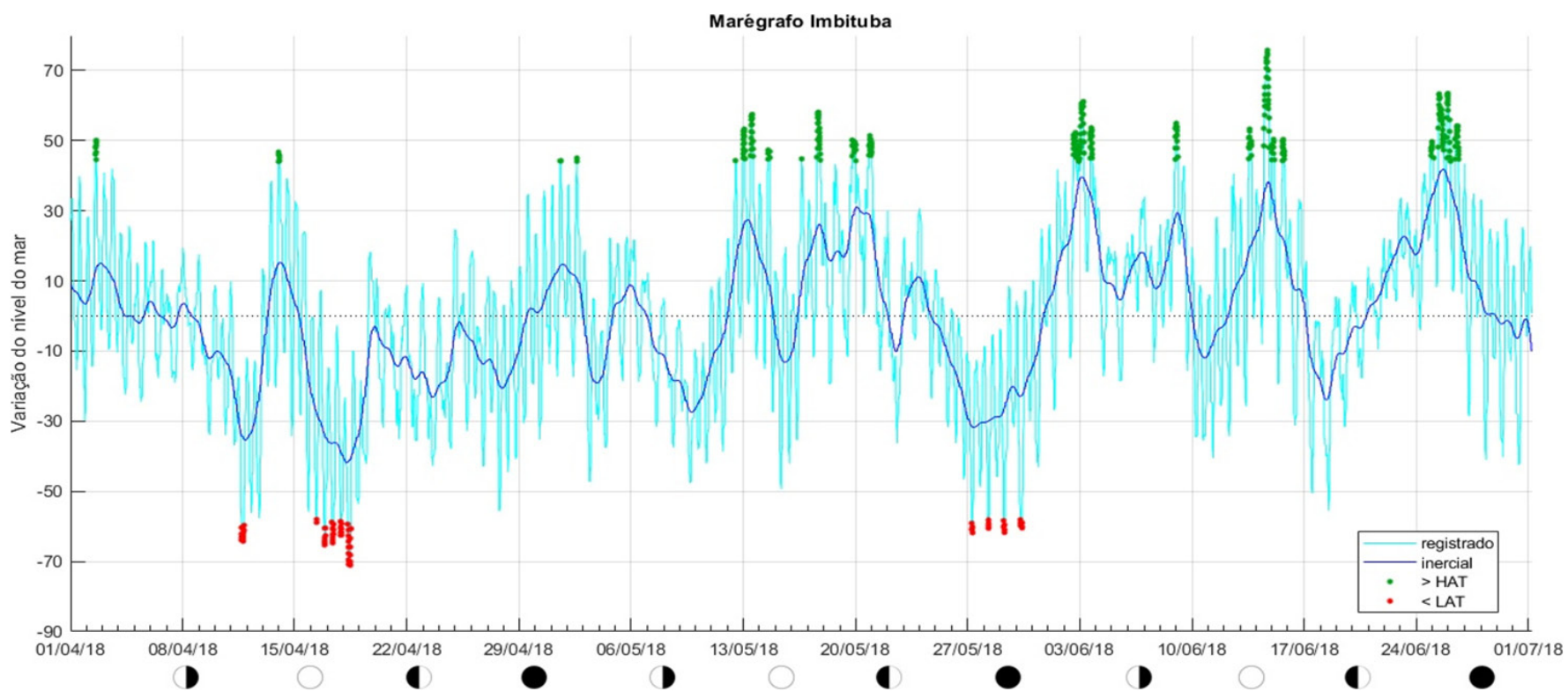

Figura 5. Flutuações do nível do mar, marés inerciais e eventos significativos observados em Imbituba no outono de 2018

Figure 5. Sea level fluctuations, inertial tides and significant events observed at Imbituba station in the fall of 2018

Tabela 3. Resumo dos eventos significativos observados em Imbituba para o outono de 2018

Table 3. Summary of significant events in fall 2018 at Imbituba monitoring station

\begin{tabular}{|l|c|c|c|c|c|c|c|c|c|}
\hline & Eventos & Total_hr & $\begin{array}{c}\text { Horas_ } \\
\text { med }\end{array}$ & $\begin{array}{c}\text { Horas_ } \\
\text { max }\end{array}$ & Obs_med Obs_max Inerc_med Inerc_max Perc_med Perc_max \\
\hline
\end{tabular}

Os pontos verdes marcam os momentos quando o nível do mar atingiu valores superiores as maiores marés astronômicas em cada localidade. De forma análoga, os pontos vermelhos marcam os momentos onde o nível do mar atingiu valores inferiores às menores marés astronômicas. Estes valores são expressos pelas siglas em inglês HAT (Highest Astronomical Tide) e LAT (Lowest Astronomical Tide), respectivamente, e representam extremos hipotéticos, quando todos os constituintes harmônicos da onda de maré estão em fase. Estes constituintes foram determinados a partir de séries históricas de cada localidade, utilizando-se modelos matemáticos harmônicos (PIROOZNIA et al., 2016). No total, obtiveram-se 86 constituintes para Florianópolis e Ilha da Paz e 72 para Imbituba e Balneário Rincão.

De forma similar, as Tabelas 1 a 4 apresentam para cada estação maregráfica um resumo dos eventos significativos do trimestre, quando o nível do mar se manteve acima dos valores de HAT (1a linha da tabela), ou abaixo dos valores de LAT (2 a linha da tabela). Para cada classe de evento os campos considerados são: número de eventos (Eventos); soma da duração de todos os eventos (Total_hr, em horas), duração média dos eventos (Horas_med, em horas); evento 


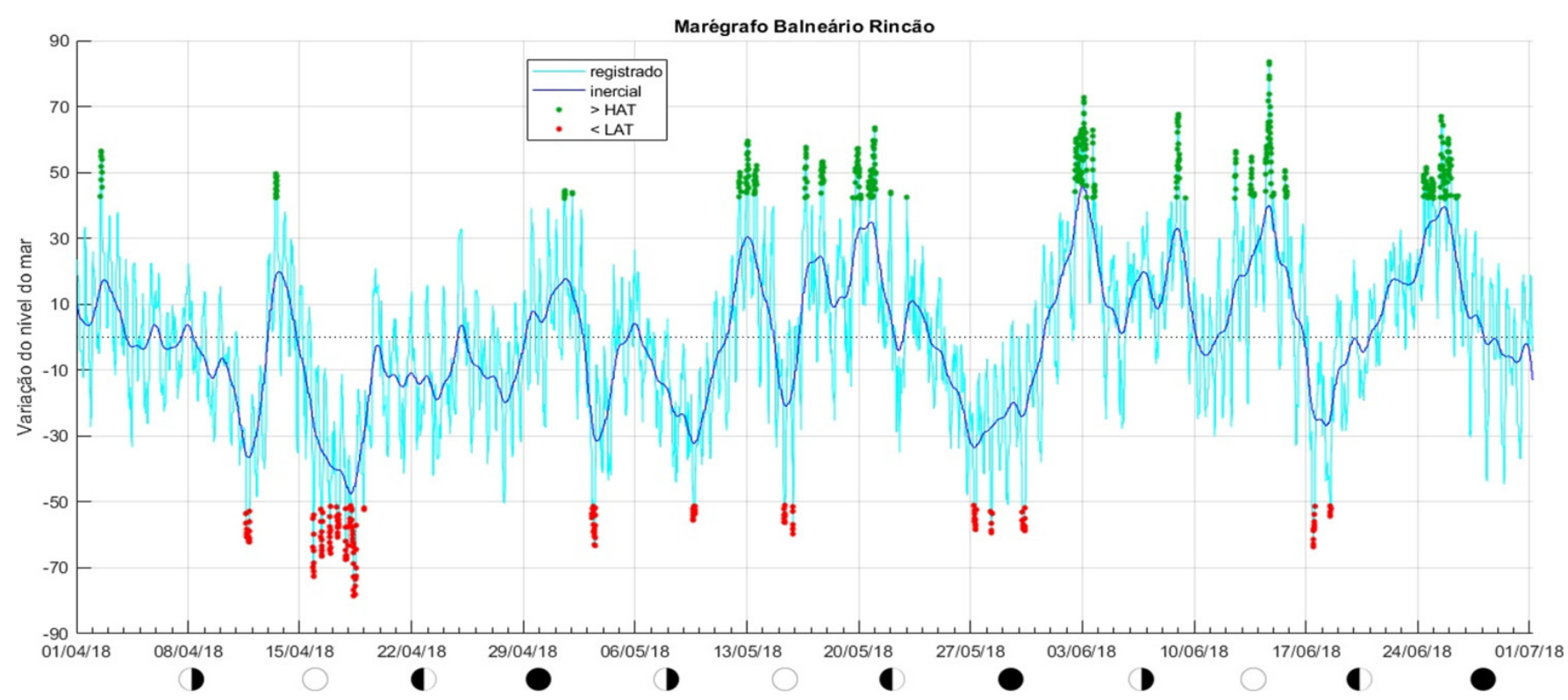

Figura 6. Flutuações do nível do mar, marés inerciais e eventos significativos observados em Balneário Rincão no outono de 2018 Figure 6. Sea level fluctuations, inertial tides and significant events observed at Imbituba station in the fall of 2018

Tabela 4. Resumo dos eventos significativos observados em Balneário Rincão para o outono de 2018

Table 4. Summary of significant events in fall 2018 at Balneário Rincão monitoring station

\begin{tabular}{|l|c|c|c|c|c|c|c|c|c|}
\hline & Eventos & Total_hr & $\begin{array}{c}\text { Horas_ } \\
\text { med }\end{array}$ & $\begin{array}{c}\text { Horas_- } \\
\text { max }\end{array}$ & Obs_med & Obs_max Inerc_med Inerc_max Perc_med Perc_max \\
\hline SHAT & 37 & 98.25 & 2.66 & 16.25 & 52 & 84 & 28 & 45 & 53 \\
\hline$<$ LAT & 23 & 47 & 2.04 & 5.5 & -52 & -54 & -32 & -47 & 62 \\
\hline
\end{tabular}

mais duradouro (Horas_max, em horas); média dos valores de nível do mar observados em todos os eventos (Obs med, em cm); máximo nível do mar observado durante os eventos (Obs_max, em $\mathrm{cm}$ ); média dos valores de maré suprainercial observados durante os eventos (Inerc_med, em $\mathrm{cm}$ ); maré suprainercial máxima observada durante os eventos (Inerc_max, em cm); média da participação percentual da maré suprainercial na variação observada do nível do mar durante os eventos (Perc_med, em \%); máxima participação percentual da maré suprainercial na variação observada do nível do mar durante os eventos (Perc_max, em \%).

A maré astronômica corresponde principalmente às variações semidiurnas (12 horas) observadas na amplitude no nível do mar e as variações de 7 dias decorrentes das alternâncias das fases da Lua (marés de sizígia e quadratura).

As marés astronômicas são menores no litoral sul do Estado e aumentam em direção ao norte. Esta diferença pode ser explicada pela distância entre estes pontos da costa catarinense e o ponto anfidrômico de maré mais próximo, localizado na plataforma continental ao sul do estado do Rio Grande do Sul (MESQUITA, 2003). Os pontos anfidrômicos são locais no oceano onde as flutuações de maré astronômica são nulas.

A maré meteorológica corresponde principalmente às variações do nível do mar observadas pelas correntes provocadas por ventos nas camadas superficiais do oceano. Estas correntes possuem direção à esquerda da velocidade do vento e precisam de aproximadamente 25 a 27 horas para se desenvolverem sobre o oceano ao largo do litoral de Santa Catarina (SC).
Dependo da intensidade, duração e pista de ventos sobre o oceano, as correntes geradas por vento podem provocar flutuações no nível do mar, empilhando ou retirando grandes volumes de água da costa. Estas flutuações do nível do mar refletem tanto o efeito do vento local quanto o de áreas remotas. Castro \& Lee (1995) mostraram que na plataforma sul do Brasil ondas livres forçadas pela elevação ou rebaixamento do nível do mar e que se propagam em direção ao Equador vindas do sul são uma das principais fontes de energia de baixa frequência (longo período) sobre a plataforma continental.

Embora este não seja o único processo que provoca sobre elevação ou rebaixamento do nível no mar na costa, ele atua como principal ator, ocorrendo muitas vezes em sinergia com outro fenômenos meteo-oceanográficos. De 
acordo com Pimenta et al. (2004), na plataforma continental de Santa Catarina, as variações do nível do mar na escala inercial, provocadas pelas forçantes meteorológicas, contribuem com $90 \%$ da energia associada ao transporte das correntes na direção meridional (aproximadamente perpendicular à linha de costa).

De uma forma geral, os registros das marés meteorológicas (Figura 2, componente suprainercial) para o outono de 2018 foram aproximadamente homogêneos para todas as localidades do litoral de Santa Catarina (SC). A pequena diferença entre as curvas revela que estas ondas de baixa frequência sofreram pouca atenuação em sua propagação de sul para norte. Interessante também notar a diferença de fase entre as curvas: os eventos registrados na llha da Paz (norte de SC) são defasados de 9 a 14 horas com relação aos mesmos eventos registrados em Balneário Rincão (sul de SC), a aproximadamente $350 \mathrm{~km}$ de distância.

Entretanto, a comparação da contribuição relativa da componente meteorológica (suprainercial) na variação total do nível do mar revelou grandes diferenças entre o litoral norte e sul do estado de Santa Catarina. Observaramse valores percentuais médios de $53 \%$ e $62 \%$, com extremos alcançando $89 \%$ e $93 \%$, nos eventos que excederam HAT e LAT respectivamente em Balneário Rincão (Tabela 4). Para a llha da Paz os valores percentuais médios observados nos eventos que excederam HAT e LAT foram $27 \%$ e $30 \%$, com extremos alcançando $46 \%$ e $34 \%$ respectivamente (Tabela 1).

No exemplo do marégrafo de Balneário Rincão (Tabela 4), para o outono de 2018, foram registrados 23 eventos num total de 47 horas em que o nível do mar esteve abaixo do mínimo astronômico (LAT) esperado para um período de 18,6 anos. Esta observação abre um questionamento sobre o uso e a confiabilidade das tábuas de maré (astronômica) para a navegação nesta região. Os níveis do mar de referência utilizados nas cartas náuticas e nas tábuas de maré levam em conta apenas as flutuações astronômicas.

Sugere-se a realização de novos estudos e projetos para viabilizar a previsão operacional do nível no mar que considerem as variações decorrentes dos fenômenos meteorológicos.

\section{Conclusão}

As alterações do nível do mar observadas no litoral de Santa Catarina e medidas pela rede de marégrafos da Epagri/Ciram são devidas a fatores astronômicos e meteorológicos.

As flutuações decorrentes da maré meteorológica são especialmente importantes para a navegação no litoral sul de Santa Catarina, onde as marés astronômicas previstas possuem amplitudes reduzidas.

O monitoramento do nível do mar realizado pela Epagri/Ciram é muito importante e relevante para a gestão adequada dos recursos costeiros, de modo que sua continuidade é um anseio das comunidades costeira e científica, não apenas em Santa Catarina, mas também para os outros estados das regiões Sul e Sudeste do Brasil.

\section{Referências}

CASTELÃO, R.M.; BARTH, J.A. Upwelling around Cabo Frio, Brazil: The importance of wind stress curl. Geophysical Research Letters, v.33, 2006

CASTRO, B.M.; LEE, T.N. Wind forced sea level variability on the southeast Brazilian Shelf. J. Geophys. Res., v.100, pp 1604516056, 1995.

ESTEBAN, M.; TAKAGI, H.; SHIBAYAMA, T. Handbook of coastal disaster mitigation for engineers and planners. Elsevier, New York, U.S.; 780 p. 2015.

FRANCO, A.S. Marés: fundamentos, análise e previsão. Ed. Diretoria de Hidrografia e Navegação, Niterói. 1997.

MESQUITA, A.R. Sea-Level Variations Along the Brazilian Coast: A Short Review. Journal of Coastal Research, Special Issue No. 35. Proceedings of the Brazilian Symposium on Sandy Beaches: Morphodynamics, Ecology, Uses, Hazards and Management. pp.21-31, 2003.

OPPENHEIM, A.V.; SCHAFER, R.W.; BUCK, J.R. Discrete-Time Signal Processing. 1999. Upper Saddle River, NJ: Prentice Hall, 870 p.

PIMENTA, F.M.; MELO FILHO, E.; FRANCO, D.; ZAVIALOV, P. Assessment of Santa Catarina Shelf Currents throught the Analysis of Indirect Measurements. Journal of Coastal Research, SI 39, p. 651-655, 2004.

RODRIGUES, M.L.G.; FRANCO, D.; SUGAHARA, S. Climatologia de frentes frias no litoral de Santa Catarina. Rev. Bras. Geof., São Paulo, v. 22, n.2, p.135-151, 2004.

STECH, J.L.; LORENZZETTI, J.A. The response of the South Brazil Bight to the Passage of Wintertime Cold Fronts. Journal of Geophysical Research, v.97, C6, 9507-9520, 1992.

PAMPUCH, L.A., AMBRIZZI, T. Sistemas Frontais sobre a América do Sul. Parte I: Climatologia e intervalo de passagem em dados da Reanálise I do NCEP/NCAR. In: Workshop Brasileiro de Micrometeorologia,9, 2015. Santa Maria - RS. Disponível em: http:// www.grec.iag.usp.br/data/arquivos_download/Pampuch_Ambrizzi_1_nova.pdf. Acesso em: 22/10/2019.

PIROOZNIA, M.; EMADI, S.R.; ALAMDARI, N.M. Caspian Sea Tidal Modelling Using Coastal Tide Gauge Data. Journal of Geological Research, vol. 2016, Article ID 6416917, 10 p., 2016. DOI: http://dx.doi. org/10.1155/2016/6416917.

PUGH, D.T. Tides, surges and mean sea level. 1987. John Wiley \& sons. Bath Typesetting Limited, Great Britain, 472p.

VANZ, A.; ARAUJO, C.E.S.; GARBOSSA, L.H.P.; BOLL, M.G. Variação da maré na costa catarinense. In: CONGRESSO LATINO-AMERICANO DE CIÊNCIAS DO MAR, 17, 2017, Balneário Camboriú. Resumos[..] Balneário Camboriú: Colacmar, 2017. p.1120-1121. 